\title{
Impact of AMSU-A Data Assimilation over High Terrains on QPFs Downstream of the Tibetan Plateau
}

\author{
Zhengkun QIN \\ Joint Center of Data Assimilation for Research and Application, \\ Nanjing University of Information and Science \& Technology, China \\ and \\ Xiaolei ZOU \\ Earth System Science Interdisciplinary Center (ESSIC), University of Maryland, Maryland, USA \\ (Manuscript received 6 January 2019, in final form 23 August 2019)
}

\begin{abstract}
The Tibetan Plateau (TP) and the atmospheric conditions over it strongly affect downstream regional weather. Advanced Microwave Sounding Unit-A (AMSU-A) brightness temperature observations provide temperature sounding information and have long been successfully assimilated for numerical weather prediction. AMSU-A brightness temperatures observed from the polar-orbiting NOAA-15 and 18 satellites during July and August 2016 were collected. During these months, the equator crossing time of these particular satellites was approximately 0600 local time. Observations collected within the 3-h periods centered at 0000 UTC and 1200 UTC, covering the TP, were assimilated. The weighting coefficients for mid-tropospheric AMSU-A channels 6 and 7 were significantly reduced over areas with terrain heights greater than $2 \mathrm{~km}$ and $4 \mathrm{~km}$, respectively, in the National Centers for Environmental Prediction Gridpoint Statistical Interpolation system. The assimilation of AMSU-A observations was improved to better exploit the role of AMSU-A channels 6 and 7 over the TP. This was achieved by not decreasing the weighting coefficients of the two channels over the grassy surface of the TP's high terrain such that they were consistent with the inverse error variances. This modification produced larger positive impacts of satellite data assimilation on the 48-h forecasts of the mid-tropospheric trough, water vapor, and quantitative precipitation forecasts downstream of the TP. This study also suggests the importance of AMSU-A observations from early-morning satellite orbits for numerical weather prediction downstream of the TP.
\end{abstract}

Keywords data assimilation; satellite data; high terrain

Citation Qin, Z., and X. Zou, 2019: Impact of AMSU-A data assimilation over high terrains on QPFs downstream of the Tibetan Plateau. J. Meteor. Soc. Japan, 97, 1137-1154, doi:10.2151/jmsj.2019-064.

Corresponding author: Xiaolei Zou, Earth System Science Interdisciplinary Center (ESSIC), University of Maryland, 5825 University Research Court, College Park, Maryland 20740-3823, USA

E-mail:xzou1@umd.edu

J-stage Advance Published Date: 13 September 2019

\section{Introduction}

Satellite data assimilation has played a key role in advancing numerical weather prediction (NWP; Bauer et al. 2015). Among the different types of satellite data, microwave temperature sounding data are among the earliest assimilated data and have played an important role in NWP. Four-channel Microwave Sounding 
Unit (MSU) instruments were onboard the first eight National Oceanic and Atmospheric Administration (NOAA) polar-orbiting satellites (i.e., NOAA-6, 7, 8, 9, 10, 11, 12, and 14). Since 1998, 15-channel Advanced Microwave Sounding Unit-A (AMSU-A) instruments have been onboard the latest five NOAA meteorological satellites (i.e., NOAA-15, 16, 17, 18, and 19) and the two new European Organization for the Exploitation of Meteorological Satellites MetOp$A$ and B. AMSU-A data from NOAA-15/18/19 and MetOp-A/B are currently routinely assimilated at major operational centers throughout the world. The 15 AMSU-A channels consist of three window channels $(1,2$, and 15$)$ with their center frequencies at 23.8, 31.4, and $89 \mathrm{GHz}$, respectively, for detecting clouds and sensing surface parameters, and 12 sounding channels evenly distributed vertically in the logarithmic pressure coordinate system to probe atmospheric temperatures throughout the troposphere and stratosphere.

Each polar-orbiting meteorological satellite circles the earth in a sun-synchronous orbit to provide global measurements of brightness temperatures twice daily and at nearly the same two local times (LTs) with a 12-h separation for a fixed geographical location. The NOAA-15/18/19, Suomi National Polar-Orbiting Partnership (S-NPP), and MetOp-A/B satellites were launched on 13 March 1998, 20 May 2005, 6 February 2009, 28 October 2011, 19 October 2006, and 17 September 2012, respectively. The local equator crossing times (LECTs) for NOAA-15/18/19, S-NPP, and MetOp-A/B were 1930, 1330, 1400, 1330, 0930, and 0930 LT, respectively, immediately after their launch times. Satellites with LECTs at approximately 0930 LT are termed mid-morning satellites (e.g., MetOp-A/ B), those with LECTs at approximately 1430 LT are termed afternoon satellites (e.g., NOAA-18/19), and those with LECTs between 0530 and 0730 LT are termed early-morning satellites (e.g., NOAA-15). Atmospheric drag and gravity and satellite aging can cause orbital drifts leading to changes in the LECT. The LECTs as of August 2016 for NOAA-15/18/19 and MetOp-A/B are 1754, 1811, 1446, 0929, and 0931 LT, respectively. NOAA-18, for example, became an early-morning satellite by August 2016 after being an afternoon satellite when it was launched. NOAA15 remains an early-morning satellite, NOAA-19 is currently an afternoon satellite, and MetOp-A/B are mid-morning satellites. Having flown for over 18 years, far exceeding its life expectancy, NOAA-15 is still operational, providing quality AMSU-A measurements except from channels 11 and 14. As shown in this study, a large portion of the Tibetan Plateau (TP) is not observed by AMSU-A onboard the mid-morning and afternoon satellites within \pm 1.5 -h data assimilation windows centered on either 0000, 0600, 1200, or 1800 UTC. Important information regarding temperature and water vapor over the $\mathrm{TP}$, atmospheric parameters that strongly affect downstream regional weather, can be missed because of the satellite data void problem.

Satellite remote sensing measurements of brightness temperature are directly assimilated using threedimensional or four-dimensional variational (3D/4Dvar) approaches (Eyre et al. 1993; Andersson et al. 1994; Derber and Wu 1998; Simmons and Hollingsworth 2002; McNally et al. 2006) in which a fast radiative transfer model serves as an observational operator to provide model simulations for a given model state (McMillin and Fleming 1976; Saunders et al. 1999, 2007; Weng 2007). Satellite data, including MSU/AMSU-A measurements, have also been assimilated to produce reanalysis products. Several studies have evaluated different reanalysis products with in situ observations made on the TP. Ma et al. (2008) showed that air temperatures over the TP from reanalysis products have the largest uncertainties in China, particularly near the edges of the TP. Zhao et al. (2015) concluded that reanalysis products underestimate the observed precipitable water by $\sim 60 \%$ over the southwestern TP. Wang and Zeng (2012) and Zhao et al. (2015) concluded that reanalysis products over the TP are consistent and unreliable and that none of the reanalysis products, i.e., state variables at daily time scales, is superior to the others. Therefore, satellite data assimilation remains challenging over high terrain.

This study assesses the impacts of satellite data assimilation on quantitative precipitation forecasts (QPFs) downstream of the TP using the National Centers for Environmental Prediction (NCEP) unified Gridpoint Statistical Interpolation (GSI) analysis system (Wu et al. 2002; Purser et al. 2003a, b) and the Advanced Research Weather Research and Forecasting (WRF) (ARW) model (Skamarock et al. 2008). In addition to brightness temperature measurements from those AMSU-A instruments onboard NOAA15/18/19 and MetOp-A/B, brightness temperature measurements from the Advanced Technology Microwave Sounder (ATMS) and the Cross-track Infrared Sounder (CrIS) onboard the S-NPP satellite and the hyperspectral Atmospheric Infrared Sounder (AIRS) onboard the National Aeronautics and Space Administration's (NASA's) Aqua satellite are also assimilated. 
Measurements from these instruments at either the microwave or infrared bands are sensitive to atmospheric temperature and water vapor at sounding channels and surface emissivity and temperature at window channels. Emphasis is placed on the assimilation of data from AMSU-A channels 6 and 7 over the TP. As shown in this study, the upstream conditions over the TP observed via satellite observations contain useful information for short-range QPFs (e.g., 0-48 h) downstream of the TP. By also eliminating the empirical reduction in the observational weighting coefficients over high terrain embedded in the GSI for AMSU-A channels 6 and 7, more improvement can be made via satellite data assimilation to QPFs than without the modification. Observations from these channels are available from the NOAA-15/18 satellites at 0000 $\mathrm{UTC} \pm 1.5 \mathrm{~h}$ and $1200 \mathrm{UTC} \pm 1.5 \mathrm{~h}$ over the TP during August 2016.

This paper is organized as follows. Section 2 provides a brief data description. Section 3 provides descriptions of the experimental design, the ARW model, and the GSI analysis system. Section 4 describes the GSI-assigned reduction in the observational weighting coefficients for AMSU-A channels 6 and 7 over terrain higher than 2 and $4 \mathrm{~km}$, respectively, and our proposed modifications, as well as four QPF score measures. Section 5 presents and compares the experimental results among only conventional data and conventional and satellite data with and without the proposed terrain modifications of AMSU-A channels 6 and 7 in terms of QPFs downstream of the TP. Section 6 provides a summary and conclusions.

\section{Data description}

Measurements of brightness temperature from AMSU-A, ATMS, AIRS, and CrIS quantify the total emitted energy from the instruments' fields of view (FOVs) in different microwave and infrared frequency bands. AMSU-A and ATMS are cross-track scanning microwave radiometers and AIRS and CrIS are crosstrack scanning hyperspectral infrared sounders for sounding the atmospheric temperature and water vapor fields. AMSU-A has 12 channels in the oxygen band frequency range of from 50.3 to $57.3 \mathrm{GHz}$ for atmospheric temperature profiling from the earth's surface to approximately $42 \mathrm{~km}$ (or $2 \mathrm{hPa}$ ). The other three AMSU-A channels are at 89, 23.8, and 31.4 GHz. The beam width mainly determines the horizontal resolution of the AMSU-A observations. The beam width is $3.3^{\circ}$ for all AMSU-A channels. There is a total of $30 \mathrm{FOVs}$ along a single scan line. The AMSU-A FOV is nearly circular at nadir with a diam- eter of approximately $48 \mathrm{~km}$ (Mo 1996). At large scan angles, the AMSU-A FOVs are elliptic. The acrosstrack diameter increases with the scan angle much more greatly than the along-track diameter, reaching a value greater than 80 and $150 \mathrm{~km}$ in the across- and along-track directions, respectively, at the largest scan angle. There is no overlap between neighboring FOVs in the across-track direction and a slight overlap between neighboring FOVs in the along-track direction at large scan angles (Zou et al. 2012). The equator crossing time for NOAA-15/18 was approximately 0600 LT during August 2016. AMSU-A observations from these two early-morning orbit satellites cover the TP within the 3-h periods centered on 0000 UTC and 1200 UTC. AMSU-A observations from NOAA-19 and MetOp-A/B were not available over most parts of the TP at all four analytical times $(0000,0600,1200$, and 1800 UTC). Figure 1 shows an example of the AMSU-A data coverage in the model domain. The TP was fully covered by two AMSU-A swaths from NOAA-18 and mostly covered by one AMSU-A swath from NOAA-15 at 1200 UTC $\pm 1.5 \mathrm{~h}$ on 14 August 2016. However, at 1800 UTC 14 August 2016, the TP was void of AMSU-A data.

The ATMS has a total of 22 channels with channels 1-16 for atmospheric temperature soundings above $\sim 1 \mathrm{hPa}$ and channels 17-22 for atmospheric humidity soundings in the troposphere below $\sim 200 \mathrm{hPa}$. Fourteen of the ATMS temperature sounding channels (channels 1-3 and 5-15) are similar to AMSU-A channels $1-14$. ATMS channels 3-16 have a beam width of $2.2^{\circ}$ and that of ATMS surface channels 1 and 2 is $5.2^{\circ}$. ATMS humidity channels $17-22$ have a beam width of $1.1^{\circ}$. The beam width differences between the ATMS and AMSU-A channels result in significant differences in FOV sizes. With their shorter integration times, ATMS temperature sounding channels are noisier than those of AMSU-A. The ATMS also has significant overlap among neighboring FOVs. ATMS observations from their overlapping FOVs are resampled to produce AMSU-A-like measurements to reduce the data noise and information redundancy. This ensures that ATMS temperature-sounding channels 1-16 have the same $3.3^{\circ}$ beam width as AMSU-A (Satellite Applications Facility for NWP, 2011). Resampled data from the 4th to 93rd FOVs at an interval of five FOVs are assimilated in the GSI (Zou et al. 2013a). The orange circles in Fig. 1 show the distribution of ATMS data. Deployed on an afternoon satellite, the ATMS only observes the eastern part of Tibet at 1800 UTC.

Conventional observations also assimilated include 


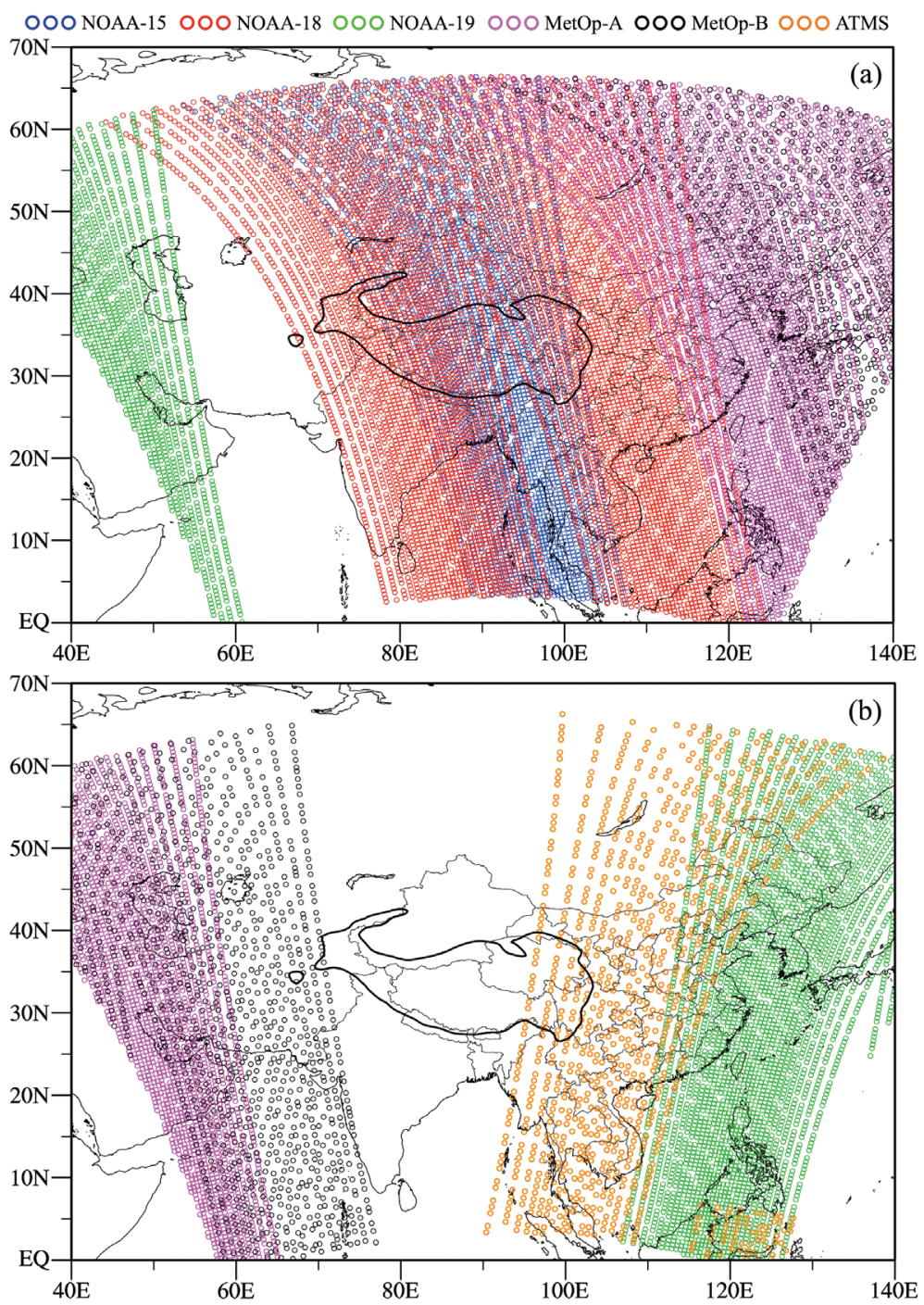

Fig. 1. Spatial distributions of AMSU-A data from NOAA-15 (blue), NOAA-18 (red), NOAA-19 (green), MetOp-A (magenta), MetOp-B (black) and ATMS (orange) at (a) $1200 \mathrm{UTC} \pm 1.5 \mathrm{~h}$ and (b) $1800 \mathrm{UTC} \pm 1.5 \mathrm{~h}$ on 14 August 2016. Parts of the Tibetan Plateau with terrain above $4 \mathrm{~km}$ are outlined by the thick black curve.

temperature, wind, and moisture from radiosondes and dropsondes, pibal-measured winds, aircraft-measured temperature and wind, surface pressure, geostationary-satellite-derived cloud drift winds, and Special Sensor Microwave Imager atmospheric total precipitable water retrievals.

\section{Experimental design}

The case selected for this study is a typical summer precipitation case that occurred at approximately 0600 UTC 15 August 2016 near the tip of a 500-hPa trough downstream of the TP. Data assimilation is conducted with a 1-day cycling at a 6-h interval from 0600 UTC 14 August to 0600 UTC 15 August 2016. The 1-day cycling period is used to avoid a potential impact from lateral boundary conditions in a regional model if a longer cycling time period is used.

The data assimilation cycling interval is $6 \mathrm{~h}$. The 6-h model forecasts from the analyses obtained at the previous times are used as the background fields except for the first data assimilation minimization conducted at 0600 UTC 14 August 2016. The NCEP Global Forecast System (GFS) analysis at 0000 UTC 14 August 2016 is used as the initial condition for 

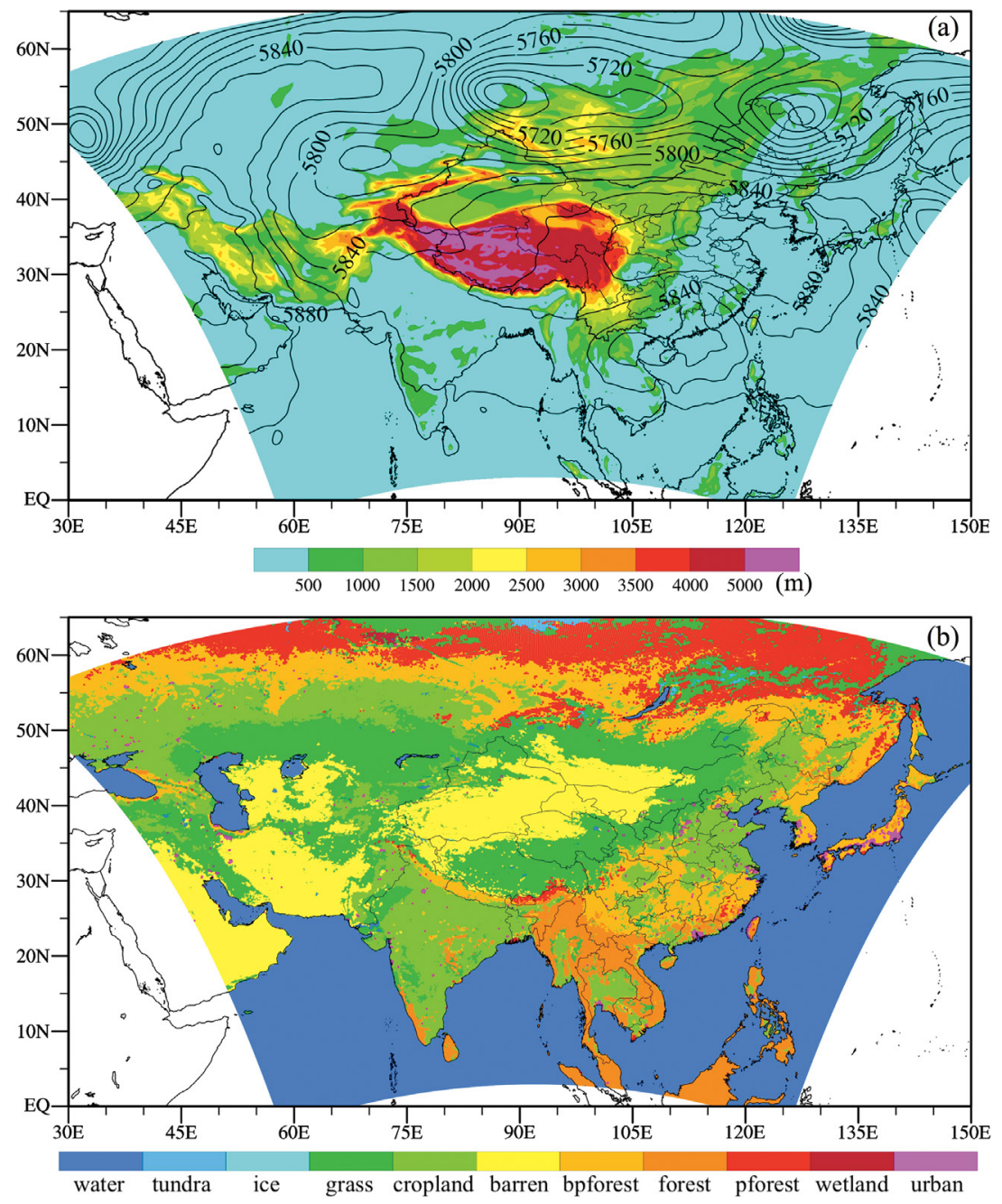

Fig. 2. (a) Spatial distribution of the 500-hPa geopotential height from the NCEP reanalysis (contour interval: $20 \mathrm{~m}$ ) and terrain height (shaded in color, unit: $\mathrm{m}$ ) in the model domain at 0000 UTC 14 August 2016. (b) Spatial distribution of the surface type is also shown in the lower panel of meadow grass (grass), croplands (cropland), barren or sparsely vegetated (barren), broadleaf forest (forest), broadleaf pine forest (bpforest), pine forest (pforest), urban and built-up (urban), wetland, ice, tundra, and water from the modified IGBP MODIS vegetation (land-use) data.

the 6-h model forecast that serves as the background field at 0600 UTC 14 August 2016. Figure 2a shows the 500-hPa geopotential height from the NCEP GFS analysis at 0000 UTC 14 August 2016, and terrain heights in the model domain. The $500-\mathrm{hPa}$ geopotential height at 0000 UTC 14 August 2016, shows a low-pressure band with multiple centers to the north and northeast of the TP, a subtropical high to the east of the TP, and a low-pressure cyclone to the southwest of the subtropical high. Steep terrain boundaries characterize the TP. Figure $2 b$ shows the spatial distribution of the land surface types from the modified
International Geosphere-Biosphere Programme (IGBP) Moderate Resolution Imaging Spectroradiometer (MODIS) vegetation (land-use) data. Grass and barren soil surface types characterize most of the high terrain of the TP.

This study employs the ARW version V3.3 forecast model. It is used to generate the 6-h forecasts during the 1-day data assimilation cycle and the 48-h model forecasts at the end of the 1-day data assimilation cycle. The model is set to a horizontal resolution of $15 \mathrm{~km}$, leading to a total of $600 \times 500$ grid points in the model domain shown in Fig. 2a. The model top is 
placed at approximately $1 \mathrm{hPa}$. There are 61 vertical levels. Zou et al. (2015) discussed the importance of assimilating the upper-level sounding channels of AMSU-A, ATMS, and AIRS. A model top higher than the 0.5 -hPa layer with more upper vertical levels is needed to resolve the upper-level sounding channels of AMSU-A, ATMS, and AIRS. The ARW runs conducted in this study use the WRF single-moment three-class microphysics scheme (Hong and Lim 2006), the Kain-Fritsch cumulus parameterization scheme (Kain and Fritsch 1990, 1993; Kain 2004), and the Yonsei planetary boundary layer scheme (Hong and Dudhia 2004). The NCEP GSI analysis system used in this study is a regional three-dimensional variational assimilation (3D-Var) system. Wu et al. (2002) described the theory behind and the development of the GSI system. We have applied this same GSI data assimilation and ARW modeling system in previous studies to assimilate measurements from geostationary operational environmental satellite imagers (Zou et al. 2011, 2015; Qin et al. 2013, 2017; Qin and Zou 2018), the MHS (Zou et al. 2013b; Qin and Zou 2016), the ATMS (Zou et al. 2013a), the AMSU-A (Zou et al. 2016), the AMSU-A and MHS combined data stream (Zou et al. 2017), and the CrIS (Li and Zou 2017).

Three data assimilation and forecast experiments were conducted. The first control experiment (CONV) assimilates all conventional observations. The second experiment (SAT) is the same as CONV except for the addition of AMSU-A, ATMS, AIRS, and CrIS satellite observations. The third experiment (SATM) is the same as SAT except that it incorporates a modification to the observational weighting coefficients of AMSU-A channels 6 and 7. Subsection 4.1 describes how the GSI system assigns AMSU-A channels 6 and 7 observational weighting coefficients over high terrain and our proposed modifications.

\section{AMSU-A observational weights and QPF scores}

\subsection{AMSU-A observational weights}

The frequencies of AMSU-A channels 6 and 7 are 54.4 and $54.94 \mathrm{GHz}$, respectively, and their peak weighting functions are approximately 400 and 250 $\mathrm{hPa}$, respectively. The observational error variances of the $i$ th AMSU-A channel from NOAA-15/18 are denoted by $\sigma_{i, \text { NOAA-15 }}^{2}$ and $\sigma_{i, \mathrm{NOAA}-18}^{2}$, respectively. The input observational errors in the GSI system for NOAA- $15 / 18$ are $\sigma_{6, \mathrm{NOAA}-15}=0.23 \mathrm{~K}$ and $\sigma_{7, \mathrm{NOAA}-15}=$ $0.25 \mathrm{~K}$ and $\sigma_{6, \mathrm{NOAA}-18}=\sigma_{7, \mathrm{NOAA}-18}=0.23 \mathrm{~K}$.

Theoretically, the observational weighting coefficients of the $i$ th AMSU-A channel from NOAA-15/18 are $\sigma_{i, \text { NOAA-15 }}^{-2}$ and $\sigma_{i, \text { NOAA-18 }}^{-2}$ However, similar to most
NWP centers, the GSI system adopts an observational weight two-step adjustment procedure depending on the terrain height because radiance simulations are difficult to conduct in these areas. Specifically, the observational weights in the GSI system are adjusted based on terrain height, surface type (e.g., sea, land, ice, snow, and others), surface air temperature, and liquid water path. The first adjustment to the observational weights for AMSU-A channels 6 and 7 are completed over regions with high terrain as follows:

$$
\begin{aligned}
\left(\sigma_{6}^{-2}\right)_{\text {GSI-terrain }} & =\left\{\begin{array}{ll}
\sigma_{6}^{-2} \times \frac{2000}{H}, & \text { if } H \geq 2000 \mathrm{~m} \\
\sigma_{6}^{-2}, & \text { if } H<2000 \mathrm{~m}
\end{array},\right. \\
\left(\sigma_{7}^{-2}\right)_{\text {GSI-terrain }} & = \begin{cases}\sigma_{7}^{-2} \times \frac{4000}{H}, & \text { if } H \geq 4000 \mathrm{~m} \\
\sigma_{7}^{-2}, & \text { if } H<4000 \mathrm{~m}\end{cases}
\end{aligned}
$$

Where, $H$ represents the terrain height at an observational location. Based on (1) and (2), observational errors increase as the terrain height increases. After the terrain adjustments, the observational errors $\left(\sigma_{6}^{-2}\right)_{\text {GSI-terrain }}$ and $\left(\sigma_{7}^{-2}\right)_{\text {GSI-terrain }}$ are greater for both NOAA-15 and NOAA-18.

The second adjustment to the observational weights is made according to the surface type (e.g., sea, land, ice, snow, and others) and surface air temperature using the following formula:

$$
\begin{array}{r}
\sigma_{i, \mathrm{SAT}}^{-2}=\frac{\sigma_{i, \mathrm{GSI}-\text { terrain }}^{-2}}{1+\sigma_{i, \mathrm{GSI}-\text { terrain }}^{-2} \times\left(f_{\varepsilon} \times \varepsilon_{i}+f_{s t} \times T_{s}\right)^{2}}, \\
\quad \text { for } i=6,7
\end{array}
$$

where $\varepsilon_{i}$ is the brightness temperature sensitivity to the surface emissivity of the $i$ th channel; $T_{s}$ represents the brightness temperature sensitivity to the surface skin temperature; $f_{\varepsilon}$ is an empirical parameter that takes on the values of $0.01,0.02,0.015,0.02$, and 0.02 for sea, land, ice, snow, and others, respectively; and $f_{\text {st }}$ is another empirical parameter that takes on the values of $0.5,2.0,1.0,2.0$, and 4.5 for sea, land, ice, snow, and others, respectively.

The GSI-adjusted observational weight distributions $\left(\sigma_{i, \mathrm{SAT}}^{-2}\right)$ used in the SAT experiment for NOAA-15 and NOAA-18 channel 6 at approximately 1200 UTC 14 June 2016, (Figs. 3a, b) shows that the observational weights over the TP where terrain heights are greater than $2 \mathrm{~km}$ are approximately an order of magnitude smaller than those over lower terrain. Similarly, the GSI-adjusted observational weights for channel 7 over 

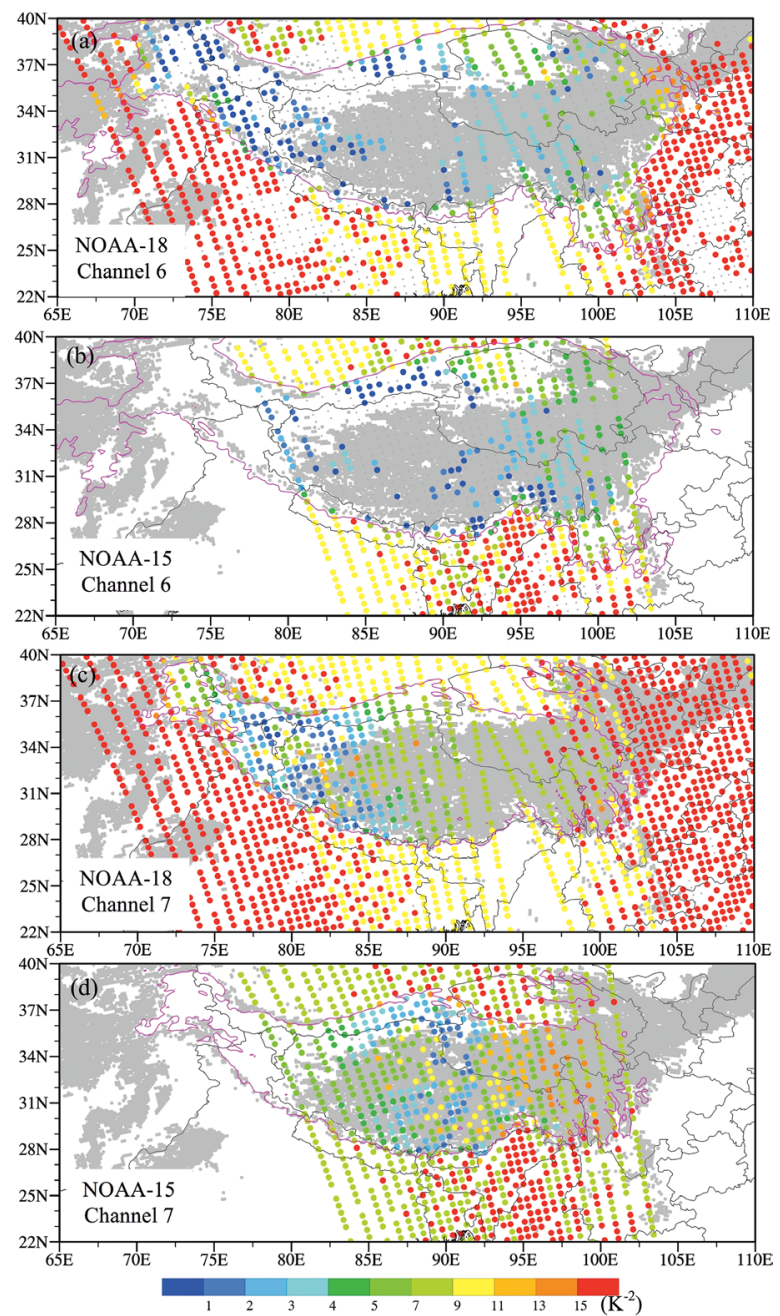

Fig. 3. The GSI-adjusted observational weights $\left(\sigma_{i, \mathrm{SAT}}^{-2}\right)$ used in the SAT experiment for channels (a)-(b) 6 and (c)-(d) 7 data from NOAA-15 and NOAA-18 at $1200 \pm 1.5$ UTC 14 June 2016 . The 2-km terrain height in (a)-(b) and the 4-km terrain height in (c)-(d) are outlined by magenta curves. Land covered by meadow grass is shown in gray.

parts of the TP with terrain heights above $4 \mathrm{~km}$ are also much smaller than those over areas with terrain heights below $4 \mathrm{~km}$ (Figs. 3c, d). Therefore, given the smaller observational weights of AMSU-A channels 6 and 7 , their roles can be reduced during the SAT data assimilation experiment.

Are these observational weight adjustments to AMSU-A channels 6 and 7 over high terrain appropriate? Variations in the $(\mathrm{O}-\mathrm{B}$; the difference between
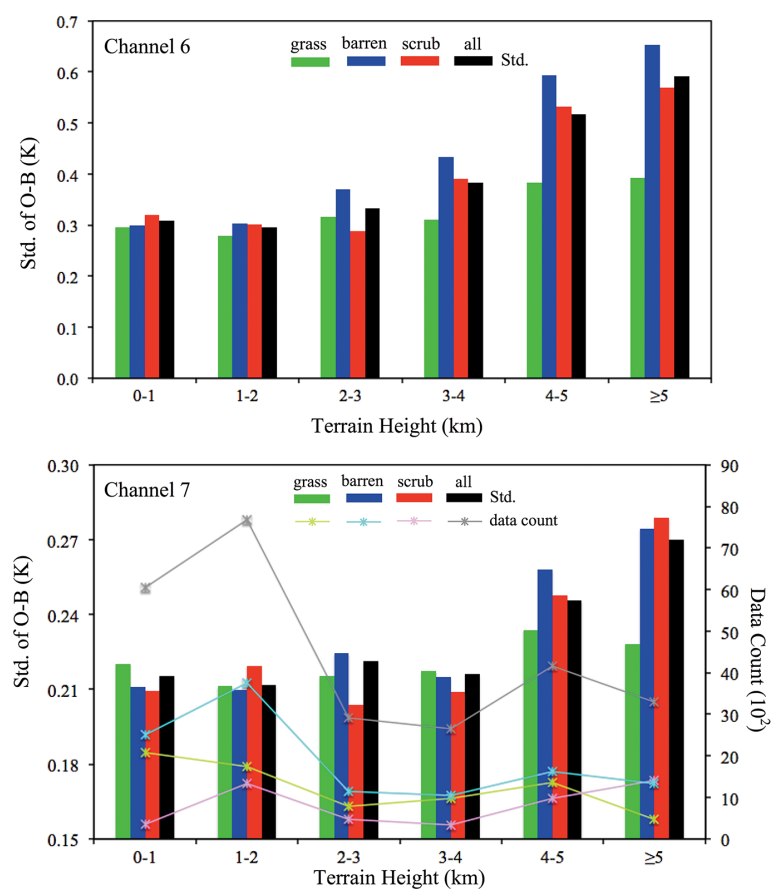

Fig. 4. Standard deviation of O-B varying with terrain height for AMSU-A channel 6 (top panel) and channel 7 (bottom panel) from NOAA 18 for clear-sky data over the TP within $22-40^{\circ} \mathrm{N}$ and $60-110^{\circ} \mathrm{E}$ for all land types (black bars), meadow grass (green bars), grass scrub (red bars), and barren soil (blue bars) during the period July 1-31, 2016. Data counts are shown with curves in the bottom panel. Clear sky data are determined according to the liquid water path (LWP $<$ $0.01 \mathrm{~g} \mathrm{~kg}^{-1}$ ) of the ERA-Interim reanalysis data.

observed and background fields) standard deviation with respect to terrain height are first examined using data from July 2016. We note that the relationship between the $(\mathrm{O}-\mathrm{B})$ standard deviation and the terrain height varies with the land surface type. Figure 4 shows the variations in the (O-B) standard deviations of AMSU-A channels 6 and 7 with respect to terrain height and land surface type. Variations in the (O-B) standard deviations over grass and other land surface types noticeably differ. For AMSU-A channel 6, the standard deviation of (O-B) significantly increases from 0.3 to $0.65 \mathrm{~K}$ over barren soil as the terrain height increases from 0 to $5 \mathrm{~km}$. However, over grass, (O-B) standard deviations slightly increase $(<0.08$ K). For AMSU-A channel 7, the standard deviation of (O-B) over grass also does not appreciably increase with terrain height. Reducing the magnitudes of the 

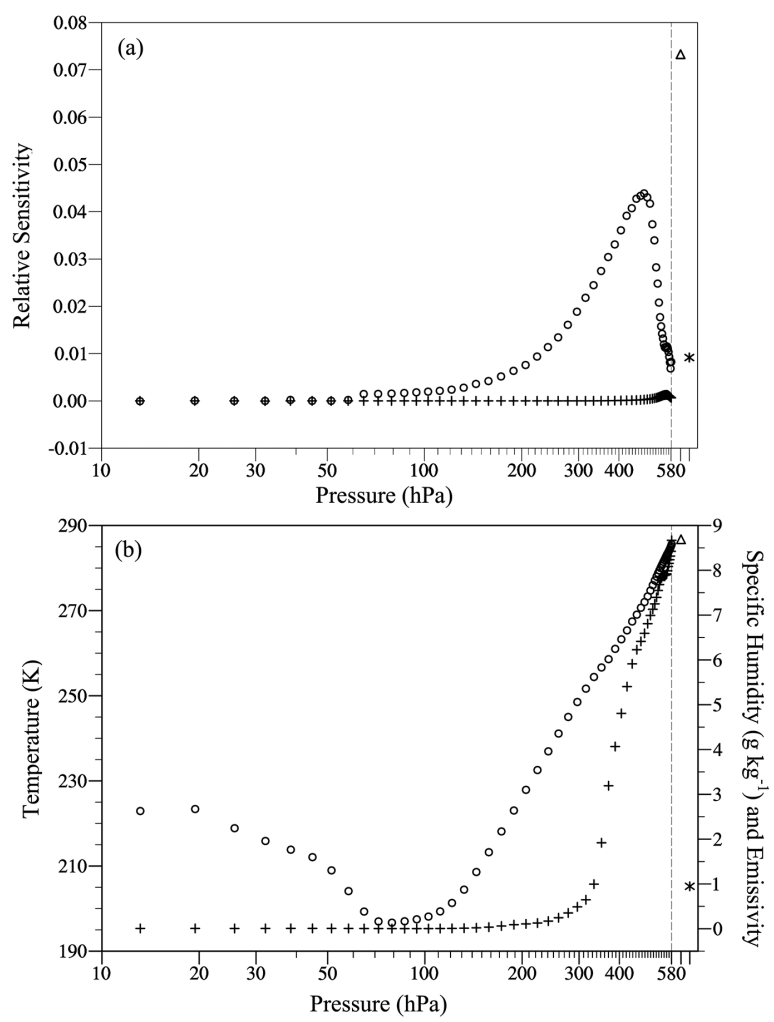

Fig. 5. (a) Relative sensitivity (upper panel) of brightness temperature to profiles of air temperature (circles) and specific humidity ("+"), surface air temperature (triangles) and surface emissivity (stars) for AMSU-A channel 6 of one grass data point with a 4673-m terrain height for NOAA-18 at $1200 \pm 1.5$ UTC 14 August 2016. The profiles of air temperature (circles) and specific humidity ("+") are also shown in (b). The position of the data point is $90.18^{\circ} \mathrm{E}, 29.27^{\circ} \mathrm{N}$. The surface emissivity corresponds to the right $y$-axis.

AMSU-A channels 6 and 7 observational weights according to terrain height is thus not needed for radiance simulations over grass. The adjustment, however, is reasonable to complete over barren soil and other surface types (e.g., scrub).

A scientific explanation of the different behaviors of radiance simulations over grass and barren soil surface types according to the terrain height follows. The method proposed and applied by Zou et al. (1993) and Carrier et al. (2008) is used to evaluate the relative sensitivity of AMSU-A channel 6 brightness temperatures to air temperature, specific humidity, surface skin temperature, and surface emissivity over grass (Fig. 5) and barren soil (Fig. 6). Figure 5a shows this relative
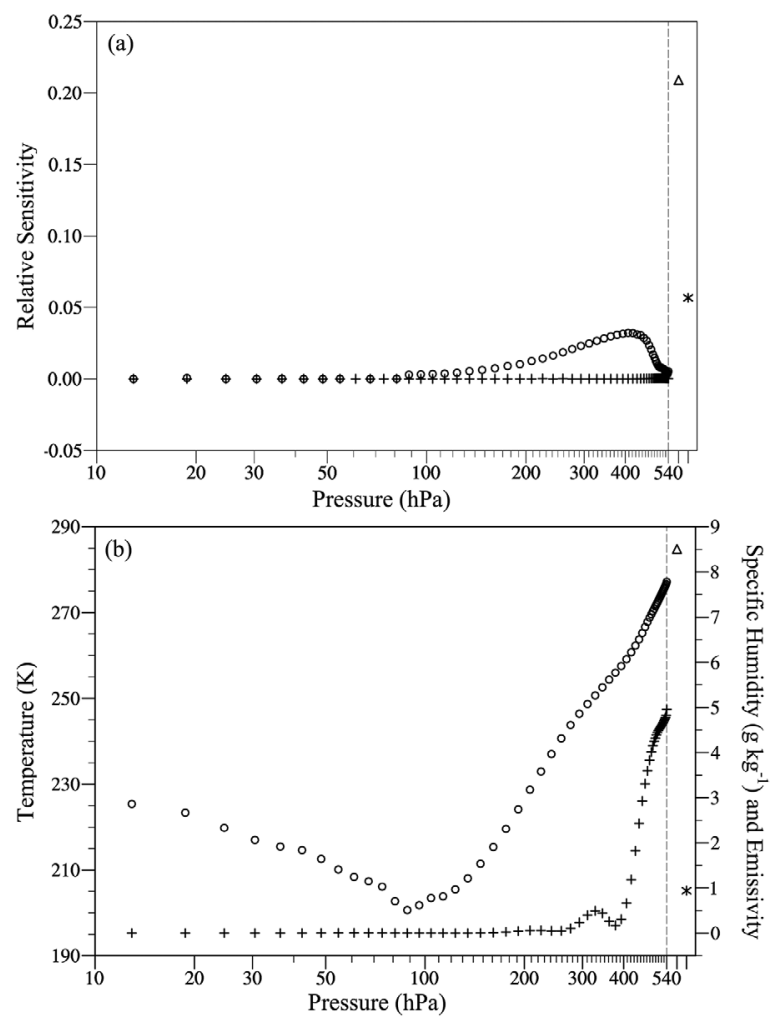

Fig. 6. (a) Relative sensitivity of brightness temperature to profiles of air temperature (circles) and specific humidity ("+"), surface air temperature (triangles) and surface emissivity (stars) for AMSU-A channel 6 of one barren soil data point with a 4898-m terrain height for NOAA-18 at $1200 \pm 1.5$ UTC 14 August 2016. The profiles of air temperature (circles) and specific humidity ("+") are also shown in (b). The position of the data point is $78.96^{\circ} \mathrm{E}, 36.09^{\circ} \mathrm{N}$. The surface emissivity corresponds to the right $y$-axis.

sensitivity over a grass data point. Figure $5 \mathrm{~b}$ shows the vertical profiles of air temperature and specific humidity as well as surface skin temperature and surface emissivity that served as the input for the brightness temperature simulations. The brightness temperature over a grass surface is most sensitive to the surface skin temperature followed by air temperature near 500 $\mathrm{hPa}$. The sensitivity to surface emissivity is lower than the sensitivities to temperature from 250 to $570 \mathrm{hPa}$. The sensitivity to specific humidity is the smallest and negligible. However, over barren soil (Fig. 6), the brightness temperature is much more sensitive to the surface emissivity than the air temperature at all altitudes. In other words, channel 6 is strongly affected 
by the barren soil surface but not by the grass surface.

Based on the results shown in Figs. 4-6, we propose to remove both the first height adjustment (Eq. 2) and the second surface adjustment (Eq. 3) for the assimilation of AMSU-A channels 6 and 7 observations over grass. The GSI two-step observational weight adjustment procedure that depends on the terrain height over barren soil and other surface types remains the same. This experiment is denoted as SATM. In other words, AMSU-A channels 6 and 7 observational weights over grass are not reduced, resulting in the increased roles of these channels in the SATM data assimilation experiment.

The two observational weights, $\sigma_{i, \mathrm{SAT}}^{-2}$ and $\sigma_{i, \mathrm{SATM}}^{-2}$, can be compared. Figure 7 shows the mean values of the observational weights calculated at NOAA-18 AMSU-A observational locations from 0000 UTC 13 August to 1800 UTC 27 August 2016. On average, the GSI adjustments defined by Eqs. (1)-(3) reduce the observational weights over high terrain $(\geq 2 \mathrm{~km})$. The modified observational weights $\left(\sigma_{i, \text { SATM }}^{-2}, i=6,7\right)$ of data over grass are significantly increased for channel $6\left(\sigma_{6 \text {, SATM }}^{-2}\right)$ when the terrain heights are above $2 \mathrm{~km}$ and for channel $7\left(\sigma_{7, \mathrm{SATM}}^{-2}\right)$ when terrain heights are above $4 \mathrm{~km}$. Below $4 \mathrm{~km}, \sigma_{7, \mathrm{SAT}}^{-2}=\sigma_{7, \mathrm{SATM}}^{-2}$. The inverse of the $(\mathrm{O}-\mathrm{B})$ variance $\left(\sigma_{i, \mathrm{O}-\mathrm{B}}^{-2}\right)$ is also shown for comparison purposes, demonstrating that $\sigma_{i, \mathrm{SATM}}^{-2}$ is nearer the inverse variance of $(\mathrm{O}-\mathrm{B})$.

The spatial locations where large modifications are made to the observational weights used in the SATM experiment are examined next. Figure 8 is similar to Fig. 3 except that only $\sigma_{i \text {, SATM }}^{-2}(i=6,7)$ is shown. Gray shading shows the grassland areas. Compared to Fig. 3 for $\sigma_{i \text { SAT }}^{-2}$, the observational weights shown in Fig. 8 are mostly larger over the grassy areas of the $\mathrm{TP}$ and remain small in the western and northern TP. Section 5 discusses the impacts of the observational weights on data assimilation and forecasts.

\subsection{QPF verification measure}

The rainfall observations used to verify the 48-h forecasts from the CONV, SAT, and SATM experiments were obtained from merging hourly rain gauge data at more than 30,000 automatic weather stations in China with the Climate Precipitation Center Morphing (CMORPH) precipitation product using a probabilitydensity-function-based optimal interpolation method (Shen et al. 2014). Quantitative measures used in comparisons among the three experiments are the equitable threat score (ETS), the Heidke skill score, the probability of detection (POD, i.e., the hit rate), and the false alarm ratio (FAR).
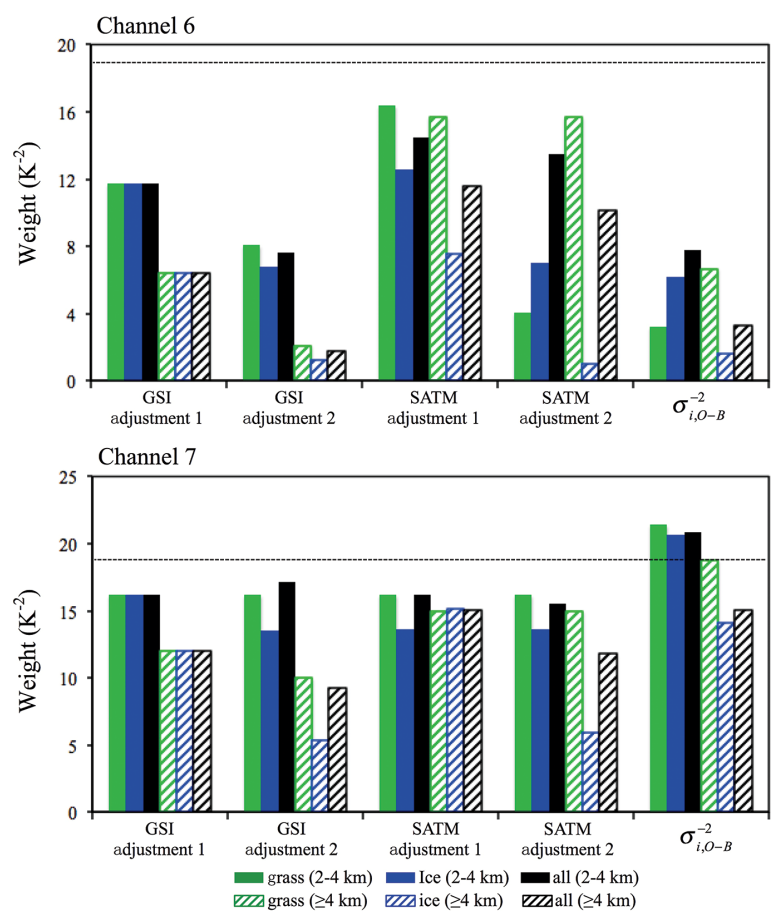

Fig. 7. Mean weights for AMSU-A channels 6 (upper panel) and 7 (down panel) from NOAA-18 data from the SAT and SATM experiment over the TP $\left(22-40^{\circ} \mathrm{N}, 60-110^{\circ} \mathrm{E}\right)$ from 0000 UTC August 13 to 1800 UTC August 27, 2016, without adjustment $\left(\sigma_{i \text {, no-adjustment }}^{-2}\right)$, (black dashed line) and after the first-step terrain height adjustment (GSI adjustment 1), the second surface emissivity and temperature adjustment (GSI adjustment 2) and the corresponding adjustment of the SATM experiment over all land types (black bars), barren soil (blue bars), and grass (green bars) surfaces. Data with a terrain height above $2 \mathrm{~km}$ is shown in solid bars and data for $4 \mathrm{~km}$ in dashed bars. The inverses of the O-B variance are also shown for comparison.

The total number of correct forecasts (hits) at a specified threshold of the observed rainfall events divided by the sum of the correct (hits) and incorrect (misses) forecasts defines the POD (Accadia et al. 2005) as follows:

$$
\mathrm{POD}=\frac{\text { hits }}{\text { hits }+ \text { misses }} .
$$

In other words, the POD represents the fraction of the observed "yes" rainfall events correctly forecasted. The largest possible value of POD is 1 , the score of a 



Fig. 8. Same as Fig. 3 except that the modified observational weights used in the SATM experiment are shown.

perfect forecast. This measure of the QPF is sensitive to correct hits but ignores false alarms and should be used in conjunction with the FAR.

The ratio of the total number of rainfall events that occur in the forecasts but not in the observations (false alarms) to the sum of false alarms and hits defines the FAR (Barnes et al. 2007) as follows:

$$
\mathrm{FAR}=\frac{\text { false alarms }}{\text { hits }+ \text { false alarms }} .
$$

The FAR is the fraction of the predicted "yes" events that did not actually occur. It also ranges from 0 to 1 . Opposite to the POD, it is sensitive to false alarms but ignores misses.

The ETS is defined as follows (Junker et al. 1992; Wilks 1995):

$$
\begin{aligned}
& \text { ETS }=\frac{\text { hits }- \text { hits }_{\text {random }}}{\text { hits }+ \text { misses }+ \text { false alarms }- \text { hits }_{\text {random }}}, \\
& \text { hits }_{\text {random }}=\frac{(\text { hits }+ \text { misses })(\text { hits }+ \text { false alarms })}{\text { total }},
\end{aligned}
$$

where hits $\mathrm{random}_{\text {is }}$ is a measure of the hits by random chance (Junker et al. 1992). An example is that it is easier to correctly forecast rain occurrences in a wet climate than in a dry climate. The hits random $_{\text {accounts }}$ for the high hits because of such a systematic model error. Therefore, the ETS indicates how well the observed "yes" rainfall events were correctly forecasted when the hits resulting from random chances (hits ${ }_{\text {random }}$ ) are eliminated. By honoring the hits and penalizing both the misses and the false alarms, the ETS allows for more fair comparisons of the QPF scores across different regimes. The ETS varies from $-1 / 3$ to 1 . The highest value of the ETS is 1, indicating a perfect rainfall forecast.

\section{Numerical results}

\subsection{Data assimilation}

One way to examine the convergence of satellite data assimilation is to compare the standard deviations of brightness temperature differences between the observations and model simulations from the background and analysis fields, i.e., (O-B) and (O-A), respectively. Figure 9 shows the standard deviations of the differences between AMSU-A observations and model simulations before and after data assimilation during the SAT and SATM experiments. All data assimilated during the 1-day cycling period are included. The number of data counts assimilated for different channels is $\sim 10^{4}$. The standard deviations of (O-B) are $\sim 0.2-0.25 \mathrm{~K}$ before data assimilation and the standard deviations of (O-A) are reduced to approximately $0.15 \mathrm{~K}$ after data assimilation.

The absolute values of the differences between the observed channel- 6 brightness temperatures and background fields $(|\mathrm{O}-\mathrm{B}|)$ and between the observed channel-6 brightness temperatures and analysis fields $(|\mathrm{O}-\mathrm{A}|)$ at AMSU-A observational locations from NOAA-18 assimilated at 1200 UTC 14 June and 1500 UTC 15 June 2016, were calculated. Figure 10 shows the spatial distributions of NOAA-18 $|\mathrm{O}-\mathrm{A}|-|\mathrm{O}-\mathrm{B}|$ for the SAT and SATM experiments and the $2-\mathrm{km}$ terrain heights. Negative values of $|\mathrm{O}-\mathrm{A}|-|\mathrm{O}-\mathrm{B}|$ imply a closer 

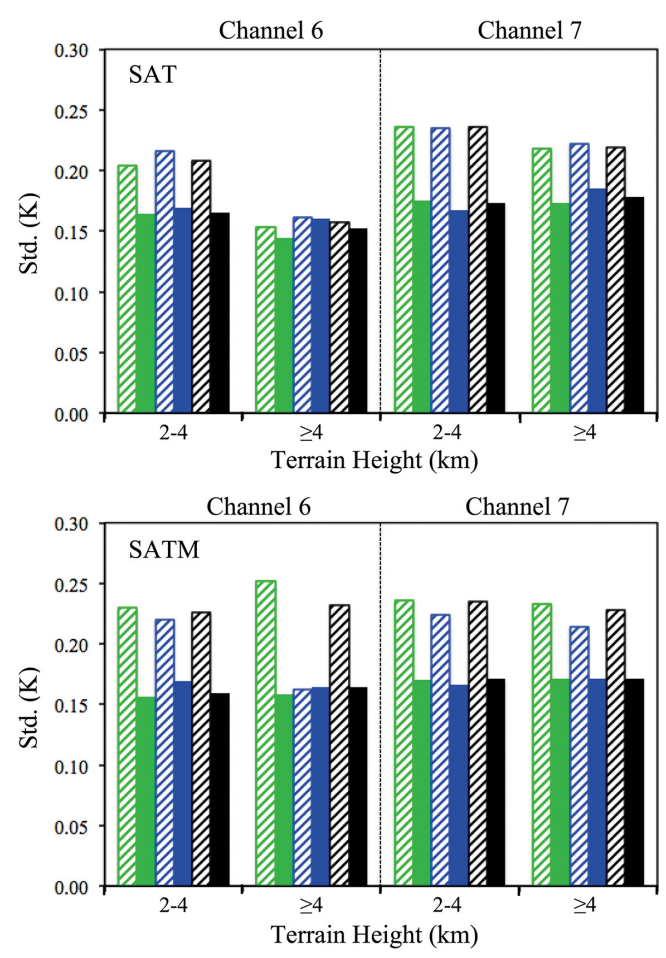

Fig. 9. Standard deviations of O-B (dashed bars) and O-A (solid bars) for data with a different terrain height over grass (green bars), barren soil (blue bars), and all land types (black bars) from AMSU-A channels 6 and channel 7 of NOAA-18 at $2-4-\mathrm{km}$ and $4-6-\mathrm{km}$ intervals from the SAT (upper panel) and SATM (down panel) at 1200 \pm 1.5 UTC 14 August and $0000 \pm 1.5$ UTC 15 August 2016. Only data from the Tibet area (22$40^{\circ} \mathrm{N}, 60-110^{\circ} \mathrm{E}$ ) are used here.

fit of the model to observations achieved via data assimilation. The channel-6 $|\mathrm{O}-\mathrm{A}|-|\mathrm{O}-\mathrm{B}|$ values from the SATM experiment are more negative than those from the SAT experiment over areas where the observational weights are increased (see Figs. 3, 8). In other words, larger observational weights produce closer fits to observations.

To show the differences in convergence among different land types, Fig. 11 shows the mean values of $|\mathrm{O}-\mathrm{A}|-|\mathrm{O}-\mathrm{B}|$ for AMSU-A channel 6 and 7 data within the terrain height ranges of $2-4 \mathrm{~km}$ and $\geqslant 4 \mathrm{~km}$ over grass, barren soil, and all land surface types from the SAT and SATM experiments within two 3-h assimilation windows of $1200 \pm 1.5$ UTC 14 August and $0000 \pm 1.5$ UTC 15 August 2016. Both experiments provide negative mean values of $|\mathrm{O}-\mathrm{A}|-|\mathrm{O}-\mathrm{B}|$ except over barren soil during the SAT experiment. This im-
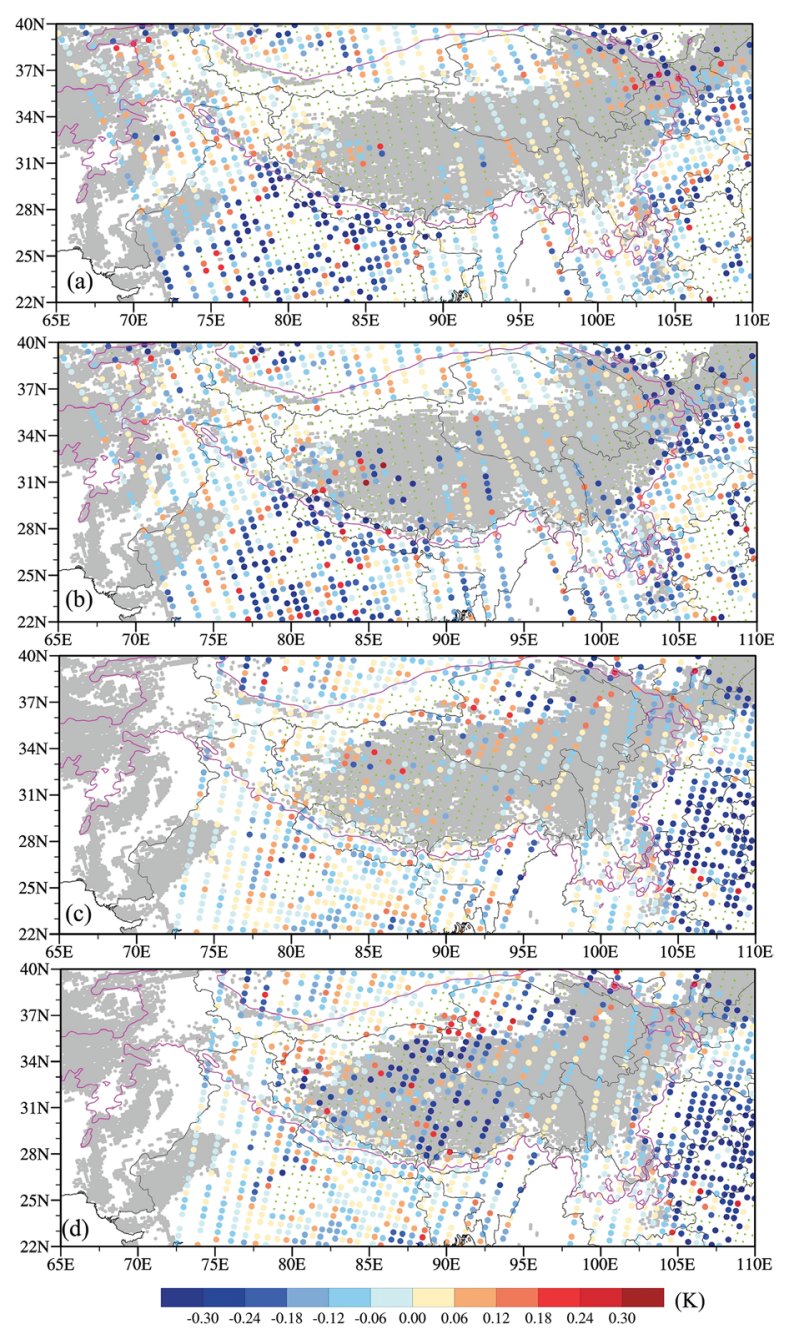

Fig. 10. Spatial distribution of $|\mathrm{O}-\mathrm{A}|-|\mathrm{O}-\mathrm{B}|$ for NOAA-18 AMSU-A channel 6 (a)-(b) within $1200 \pm 1.5$ UTC August 14 and (c)-(d) within $0000 \pm 1.5$ UTC August 15, 2016, in the SAT (a, c)) and SATM (b, d) experiments. The 2-km terrain height is indicated by the purple curve. Land covered by meadow grass is shown in gray.

plies that minimization converges well during the data assimilation. Note that in the SATM experiment, $|\mathrm{O}-\mathrm{A}|$ is significantly smaller than $|\mathrm{O}-\mathrm{B}|$ over grassy areas of the TP where the terrain height is greater than $2 \mathrm{~km}$, particularly for AMSU-A channel 6.

The different degrees of fits to observations originate from differences in the analyses. Figure 12 shows the spatial distributions of the 500-hPa specific humidity analyses between the SATM and the SAT analyses at 1200 and 1800 UTC 14 August and 0000 and 0600 


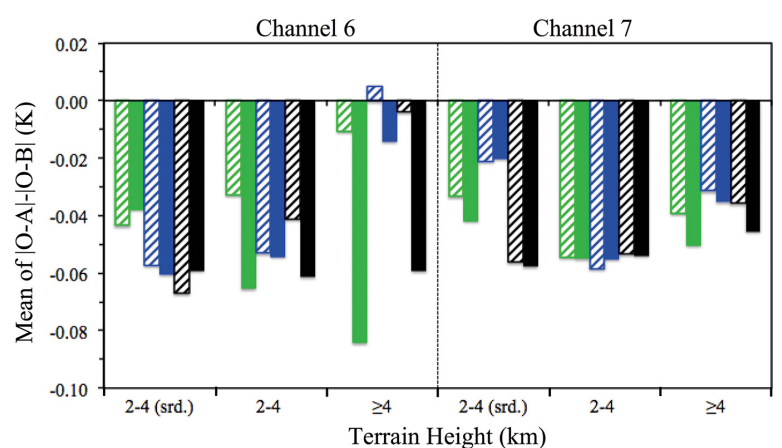

Fig. 11. Mean values of $|\mathrm{O}-\mathrm{A}|-|\mathrm{O}-\mathrm{B}|$ for AMSU-A channels 6 and 7 data within the terrain height ranges of 2-4 km and $\geqslant 4 \mathrm{~km}$ over grass (green bars), barren soil (blue bars) and all land surface types (black bars) from the SAT (dashed bars) and SATM (solid bars) within two 3-h assimilation windows of $1200 \pm 1.5$ UTC 14 August and $0000 \pm 1.5$ UTC 15 August 2016. Results for data in the remaining model area excluding the Tibet area $\left(22-40^{\circ} \mathrm{N}, 60-110^{\circ} \mathrm{E}\right)$ are shown in the first group indicated by " $2-4$ (srd.)".

UTC 15 August 2016. The specific humidity analyses at $500 \mathrm{hPa}$ obtained during the SATM experiment are wetter by approximately $1 \mathrm{~g} \mathrm{~kg}^{-1}$ than those from the SAT experiment over the TP, particularly near it eastern edges. These are areas in the northern part of the subtropical high located over and east of the TP (see Fig. 13).

\subsection{Model forecasts}

Figure 13 shows the $500-\mathrm{hPa}$ geopotential height fields from the NCEP GFS analysis (Fig. 13a) and the SATM analysis (Fig. 13b) at 0600 UTC 15 August 2016. Also shown is the 3 -h accumulated rainfall during the period 0600-0900 UTC 15 August 2016, from observations (Fig. 13a) and the SATM forecast (Fig. 13b). The southerly and westerly flows over these regions result in increased water vapor in the downstream area of the TP. There was a weak 500$\mathrm{hPa}$ trough downstream of the TP at approximately $37^{\circ} \mathrm{N}$ at 0600 UTC 15 August 2016, which is the end time of the SATM data assimilation cycle (Fig. 13b). The NCEP GFS analysis fails to capture this trough. Hourly rain gauge data from more than 30,000 automatic weather stations in China merged with the CMORPH precipitation product show a 3 -h accumulated rainfall amount of $\sim 20 \mathrm{~mm}$ during the period 0600-0900 UTC 15 August 2016 (Fig. 13a). The 3-h rainfall forecasted by the SATM experiment occurs
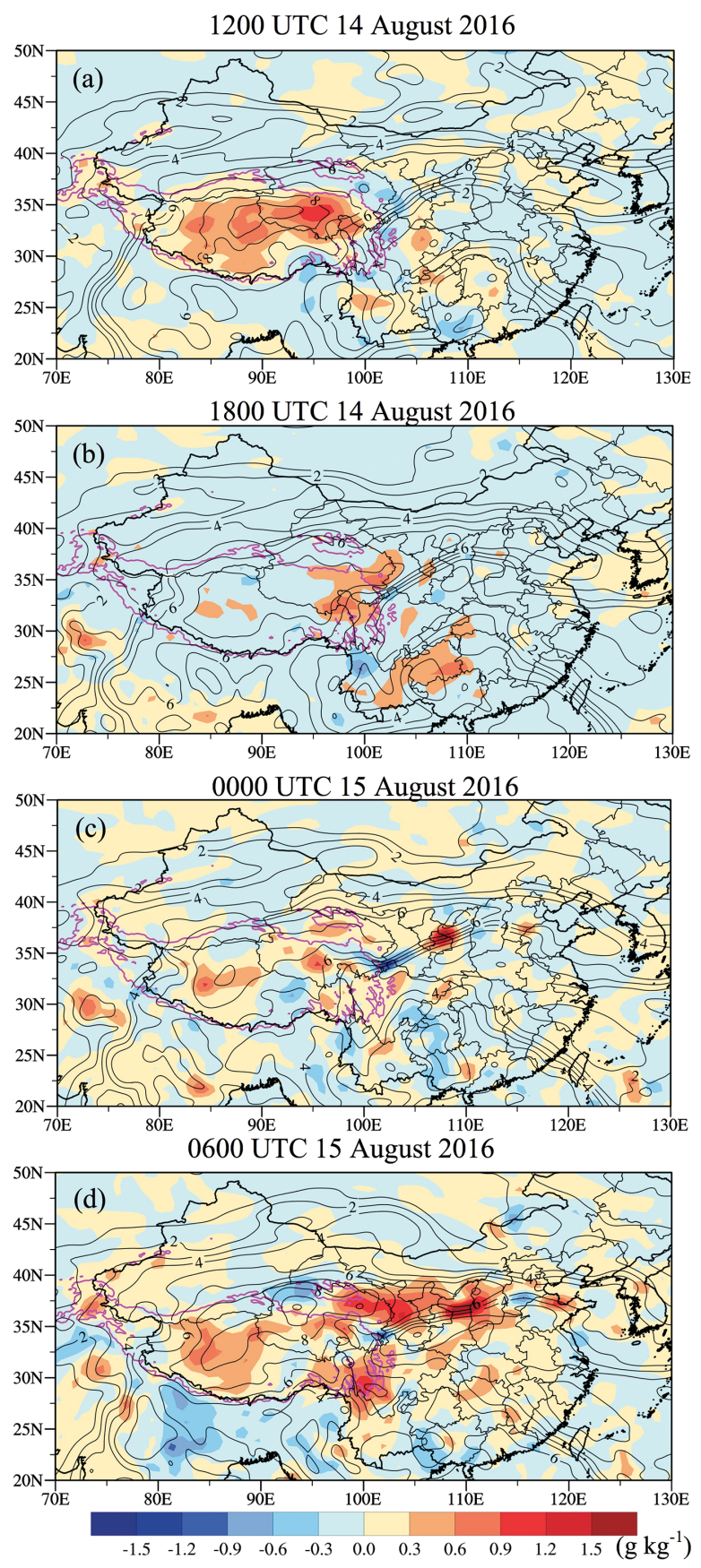

Fig. 12. Spatial distributions of the 500-hPa specific humidity analysis from the SATM experiment (black contours, unit: $\mathrm{g} \mathrm{kg}^{-1}$ ) and analysis field differences between the SATM and SAT experiments (SATM-SAT, shaded in color, unit: $\mathrm{g} \mathrm{kg}^{-1}$ ) at (a) 1200, (b) 1800, (c) 2400 UTC 14 and (d) 0600 UTC 15 August 2016. 


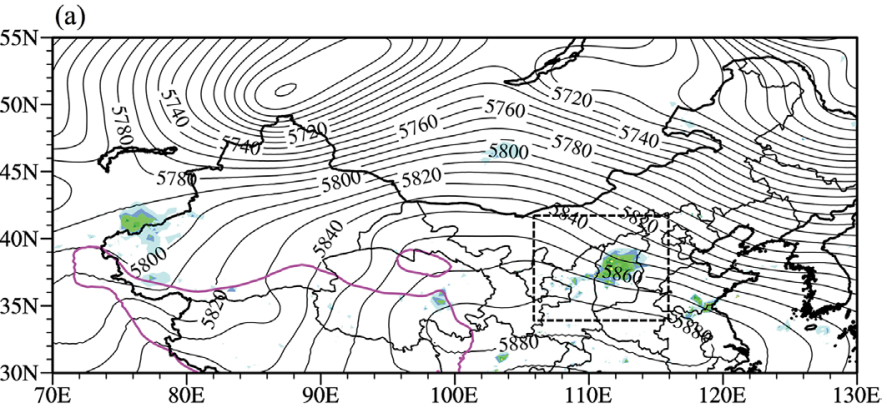

(b)

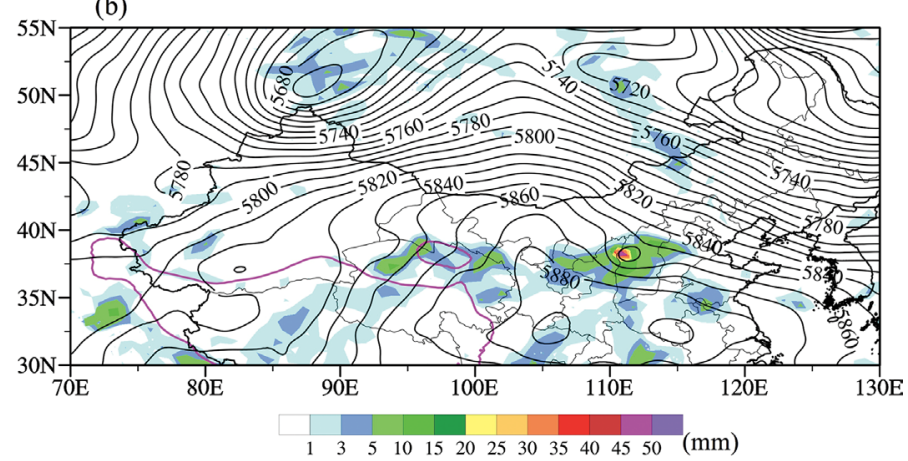

Fig. 13. Spatial distributions of the 3-h accumulated rainfall during the period 0600-0900 UTC 15 August 2016 (shaded in color, unit: $\mathrm{mm}$ ) from (a) observations and (b) the initial 3-h SATM forecast. The black contours in each panel are the 500-hPa geopotential heights (unit: gpm) at 0600 UTC 15 August 2016, from GFS analysis data and WRF forecast of the SATM experiment. The magenta contours outline areas with terrain heights above $4 \mathrm{~km}$. The black dashed square in (a) shows the rainfall validation area.
Fig. 14. Mean differences (left panels) and standard deviations (right panels) of the differences in (a)-(b) specific humidity and (c)-(d) temperature between radiosonde observations (50 radiosonde stations occur within the domain of $30-45^{\circ} \mathrm{N}, 80-$ $120^{\circ} \mathrm{E}$ ) and 48 -h forecasts from the CONV (black), SAT (red), and SATM (blue) experiments (1200 UTC 15 August to 0600 UTC 17 August 2016).
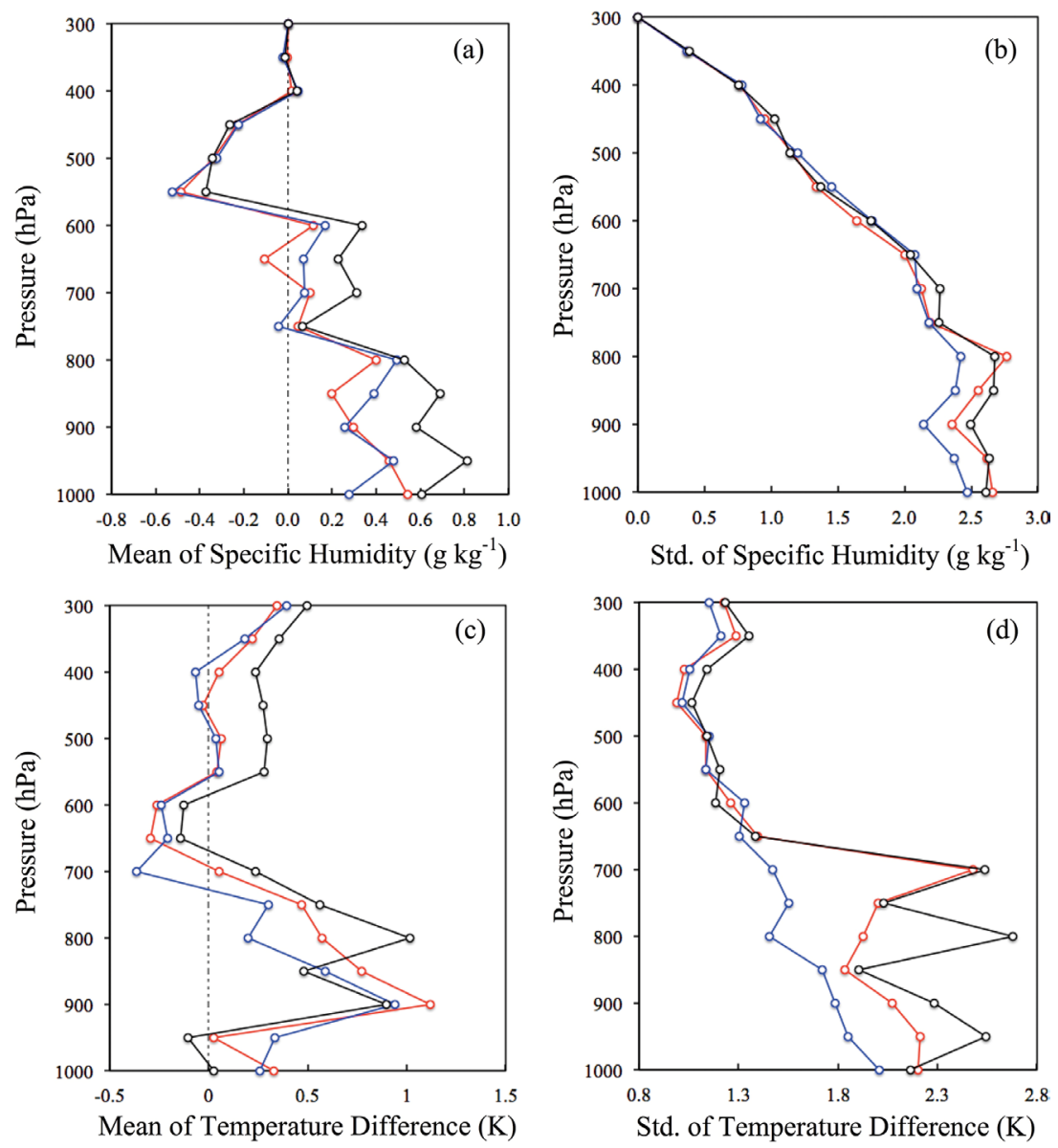

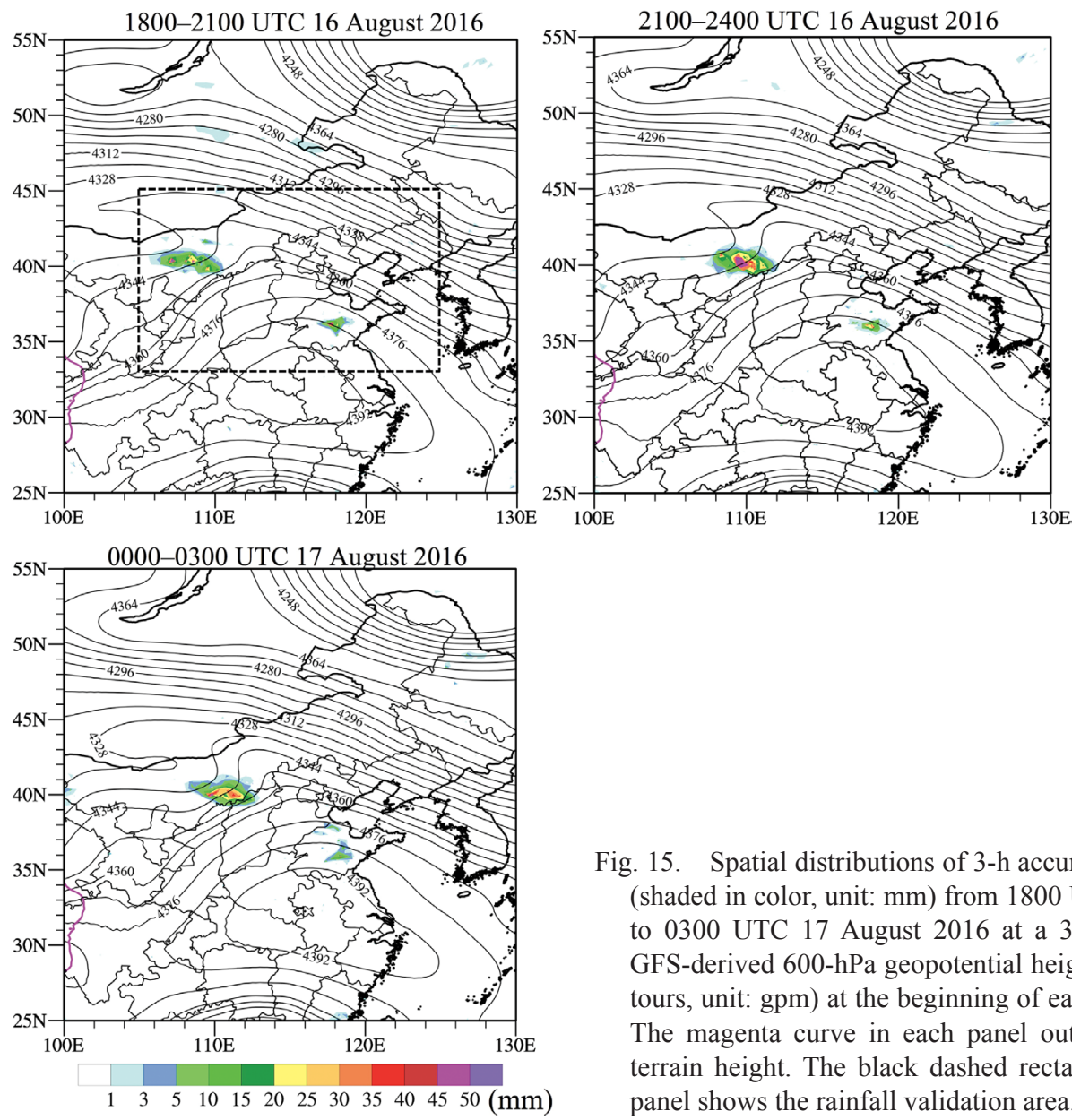

Fig. 15. Spatial distributions of 3-h accumulated rainfall (shaded in color, unit: mm) from 1800 UTC 16 August to 0300 UTC 17 August 2016 at a 3-h interval and GFS-derived 600-hPa geopotential heights (black contours, unit: gpm) at the beginning of each 3-h window. The magenta curve in each panel outlines the 4-km terrain height. The black dashed rectangle in the top panel shows the rainfall validation area.

near the 500-hPa trough location and geographically coincides with the observed rainfall. The forecasted rainfall amount is greater in magnitude than the observed rainfall amount.

In addition, rainfall and radiosonde observations can be used to validate model forecasts. There are 50 radiosonde stations within the domain of $30-45^{\circ} \mathrm{N}$ of $80-120^{\circ} \mathrm{E}$. Figure 14 shows the mean differences and standard deviations of the differences in specific humidity (Figs. 14a, b) and temperature (Figs. 14c, d) between the 48-h forecasts from the three numerical forecast experiments and radiosonde observations from 1200 UTC 15 August to 0600 UTC 17 August 2016. The 48-h forecasts of both the temperature and specific humidity fields from the SAT and SATM experiments agreed better with the radiosonde observations than those from the CONV experiment, except for slightly larger negative biases of specific humidity at approximately $580 \mathrm{hPa}$ and of temperature at approximately $600-650 \mathrm{hPa}$. The specific humidity forecasts arising from the modified satellite data assimilation, i.e., the SATM experiment, show the greatest improvement. The smallest mean differences from this experiment are below $600 \mathrm{hPa}$. The largest reduction in the mean error $\left(\sim 0.7 \mathrm{~g} \mathrm{~kg}^{-1}\right)$ occurs in the $800-900-\mathrm{hPa}$ layer. The standard deviations for temperature and specific humidity below $750 \mathrm{hPa}$ are also reduced by the satellite data assimilation (Figs. 14b, d).

A heavy precipitation episode occurred during the $36-45-\mathrm{h}$ period of the model forecasts. Figure 15 shows the spatial distributions of the 3-h accumulated rainfall observations from 1800 UTC 16 August (36-h forecast) to 0300 UTC 17 August (45-h forecast), 2016, as well as the $600-\mathrm{hPa}$ geopotential height from the NCEP GFS analysis at the beginning of each 3-h rainfall window. This precipitation event occurred near a northwest/southeast-oriented trough at approximately $38^{\circ} \mathrm{N}$. The spatial distribution of the $3-\mathrm{h}$ accumulated rainfall during the 39-42 forecast hours, corresponding to 2100-2400 UTC 16 August 2016, 
shows a major area of precipitation in the northwest and a smaller precipitation area in the southeast (Fig. 16a). These areas of precipitation are well captured by the SAT and SATM experiments (Figs. 16c, d), although the precipitation area at the southeastern location has a westward shift. Located on the north side of the subtropical high downstream of the TP is this southeastern precipitation area. The CONV experiment predicted a continuous band of precipitation (Fig. 16b).

Figure 17 shows the QPF skill measures. Except for the 36-39-hforecasts at the 1- and 5-mm thresholds, the SATM experiment outperforms the CONV experiment. The ETS values for the SAT experiment are lower than those of the CONV experiment at several forecast times and rainfall thresholds. Because of the much larger area of precipitation, the POD values from the CONV experiment are the highest (Fig. 17b) and the FAR values are also the highest (Fig. 17c). Comparing POD and FAR between the SAT and SATM experiments, the POD (FAR) values of precipitation during the 36-45-h forecasts generated by the SATM experiment are higher (lower) than those of the SAT experiment.

\section{Summary and conclusions}

In this study, we demonstrated the benefits of satellite data assimilation for improved QPFs downstream of the TP. Satellite data assimilation generated an otherwise missing 500-hPa trough over the observed precipitation region. We also showed how mid-tropospheric AMSU-A channels 6 and 7 assimilated over high terrain matter for regional weather forecasts that are strongly affected by the upstream atmospheric conditions over the TP. A wetter atmosphere over the TP contributed to more accurate forecasts for specific humidity in the middle and low troposphere and better QPFs over southeast China. These preliminary results highlight the potential benefits of re-examining satellite data assimilation details over high terrain. This study uses a 3-h assimilation window in a 6-h cycle, which provided better QPFs than both the 3-h window in the 3-h cycle and 6-h window in a 6-h cycle (figure omitted). Therefore, only satellite observations that cover the TP within the 3-h window were assimilated. Because more satellite observations are available within a 6-h assimilation window, further investigations are required to explore the benefits of these unused satellite observations.

The TP occupies a large geographical area with very high terrain that is uninhabitable. Conventional observations are scarce in the area. With more than
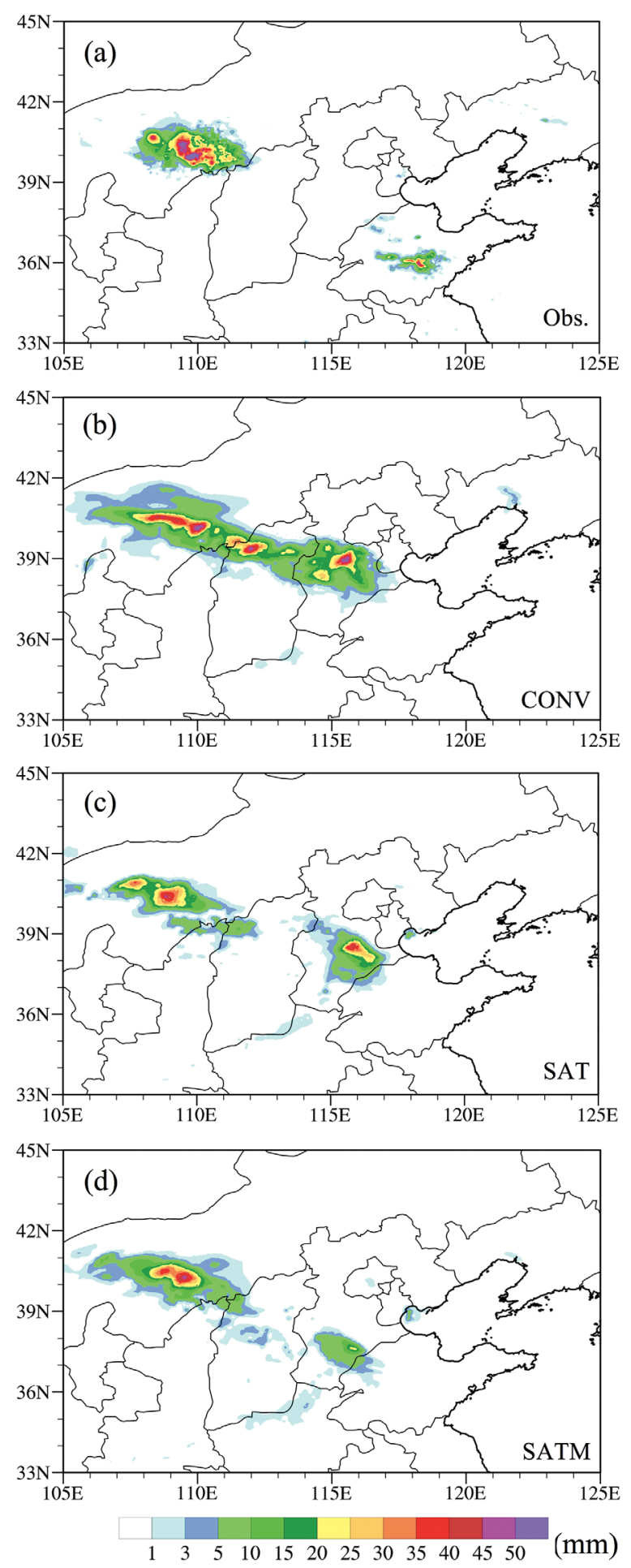

Fig. 16. Three-hour accumulated rainfall (shaded in color, unit: $\mathrm{mm}$ ) distributions (39-42 forecast hours) during the period 2100-2400 UTC 16 August 2016, from (a) observations and the (b) CONV, (c) SAT, and (d) SATM experiments. 

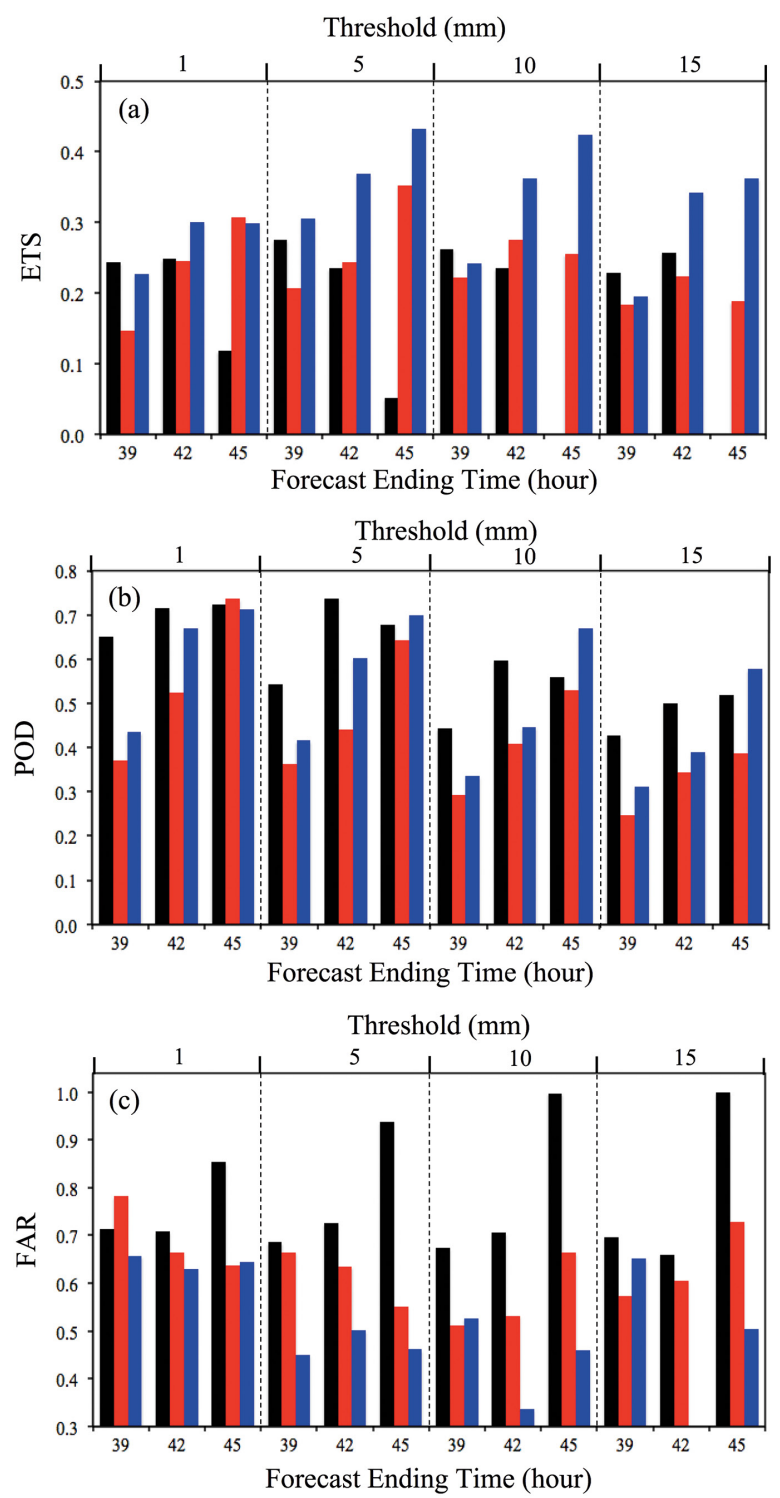

Fig. 17. (a) ETS, (b) POD, and (c) FAR of the 3-h accumulated rainfall at the 1-, 5-, 10-, and 15 $\mathrm{mm}$ thresholds during the $39-45-\mathrm{h}$ forecasts (i.e., from 1800 UTC 16 August to 0300 UTC 17 August 2016). The black, red, and blue bars are for the CONV experiment, SAT experiment, and SATM experiment, respectively.

40 years of continuous data records, MSU/AMSU-A/ ATMS measurements have been the key data types assimilated to produce reanalysis products at major research centers throughout the world. As increasingly more satellite observations over the TP continue to be made, this work will inspire accelerated advancement of satellite data assimilation focused on this part of the world. This is important not only for NWP but also for reanalysis data production. It will also guide those wishing to use reanalysis products over high terrain and for downstream weather prediction.

\section{Acknowledgments}

This research was jointly supported by the National Key R\&D Program of China under the support of Grant 2018YFC1507302 and the National Natural Science Foundation of China (No. 91730304 and No. 91337218). The authors would like to thank M. C. Cribb for editing the manuscript.

\section{References}

Accadia, C., S. Mariani, M. Casaioli, A. Lavagnini, and A. Speranza, 2005: Verification of precipitation forecasts from two limited-area models over Italy and comparison with ECMWF forecasts using a resampling technique. Wea. Forecasting, 20, 276-300.

Andersson, E., J. Pailleux, J.-N. Thépaut, J. R. Eyre, A. P. McNally, G. A. Kelly, and P. Courtier, 1994: Use of cloud-cleared radiances in three/four-dimensional variational data assimilation. Quart. J. Roy. Meteor. Soc., 120, 627-653.

Barnes, L. R., E. C. Gruntfest, M. H. Hayden, D. M. Schultz, and C. Benight, 2007: False alarms and close calls: A conceptual model of warning accuracy. Wea. Forecasting, 22, 1140-1147.

Bauer, P., A. Thorpe, and G. Brunet, 2015: The quiet revolution of numerical weather prediction. Nature, 525, 47-55.

Carrier, M. J., X. Zou, and W. M. Lapenta, 2008: Comparing the vertical structures of weighting functions and adjoint sensitivity of radiance and verifying mesocale forecasts using AIRS radiance observations. Mon. Wea. Rev., 136, 1327-1348.

Derber, J. C., and W.-S. Wu, 1998: The use of TOVS cloudcleared radiances in the NCEP SSI analysis system. Mon. Wea. Rev., 126, 2287-2299.

Eyre, J. R., G. A. Kelly, A. P. McNally, E. Andersson, and A. Persson, 1993: Assimilation of TOVS radiance information through one-dimensional variational analysis. Quart. J. Roy. Meteor. Soc., 119, 1427-1463.

Hong, S.-Y., and J. Dudhia, 2004: Testing of a new nonlocal boundary layer vertical diffusion scheme in numerical weather prediction applications. 20th Conference on Weather Analysis and Forecasting/16th Conference on Numerical Weather Prediction, Seattle, WA, 17.3 p. [Available at https://ams.confex.com/ams/84Annual/ techprogram/paper_72744.htm.]

Hong, S.-Y., and J.-O. J. Lim, 2006: The WRF singlemoment 6-class microphysics scheme (WSM6). J. Korean Meteor. Soc., 42, 129-151. 
Junker, N. W., J. E. Hoke, B. E. Sullivan, K. F. Brill, and F. J. Hughes, 1992: Seasonal and geographic variations in quantitative precipitation prediction by NMC's nested-grid model and medium-range forecast model. Wea. Forecasting, 7, 410-429.

Kain, J. S., 2004: The Kain-Fritsch convective parameterization: An update. J. Appl. Meteor, 43, 170-181.

Kain, J. S., and J. M. Fritsch, 1990: A one-dimensional entraining/detraining plume model and its application in convective parameterization. J. Atmos. Sci., 47, 2784-2802.

Kain, J. S., and J. M. Fritsch, 1993: Convective parameterization for mesoscale models: The Kain-Fritsch scheme. The Representation of Cumulus Convection in Numerical Models. Emanuel, K. A., and D. J. Raymond (eds.), Meteorological Monographs book series, Amer. Meteor. Soc., 165-170.

Li, X., and X. Zou, 2017: Bias characterization of CrIS radiances at 399 selected channels with respect to NWP model simulations. Atmos. Res., 196, 164-181.

Ma, L., T. Zhang, Q. Li, O. W. Frauenfeld, and D. Qin, 2008: Evaluation of ERA-40, NCEP-1, and NCEP-2 reanalysis air temperatures with ground-based measurements in China. J. Geophys. Res., 113, D15115, doi:10.1029/2007JD009549.

McMillin, L. M., and H. E. Fleming, 1976: Atmospheric transmittance of an absorbing gas: A computationally fast and accurate transmittance model for absorbing gases with constant mixing ratios in inhomogeneous atmospheres. Appl. Opt., 15, 358-363.

McNally, A. P., P. D. Watts, J. A. Smith, R. Engelen, G. A. Kelly, J. N. Thépaut, and M. Matricardi, 2006: The assimilation of AIRS radiance data at ECMWF. Quart. J. Roy. Meteor. Soc., 132, 935-957.

Mo, T., 1996: Prelaunch calibration of the advanced microwave sounding unit-A for NOAA-K. IEEE Trans. Microwave Theory Tech., 44, 1460-1469.

Purser, R. J., W.-S. Wu, D. F. Parrish, and N. M. Roberts, 2003a: Numerical aspects of the application of recursive filters to variational statistical analysis. Part I: Spatially homogeneous and isotropic Gaussian covariances. Mon. Wea. Rev., 131, 1524-1535.

Purser, R. J., W.-S. Wu, D. F. Parrish, and N. M. Roberts, 2003b: Numerical aspects of the application of recursive filters to variational statistical analysis. Part II: Spatially inhomogeneous and anisotropic general covariances. Mon. Wea. Rev., 131, 1536-1548.

Qin, Z., and X. Zou, 2016: Development and initial assessment of a new land index for microwave humidity sounder cloud detection. J. Meteor. Res., 30, 12-37.

Qin, Z., and X. Zou, 2018: Direct assimilation of ABI infrared radiances in NWP models. IEEE J. Sel. Top. Appl. Earth Obs. Remote Sens., 11, 2022-2033.

Qin, Z., X., Zou, and F. Weng, 2013: Evaluating added benefits of assimilating GOES imager radiance data in GSI for coastal QPFs. Mon. Wea. Rev., 141, 75-92.
Qin, Z., X. Zou, and F. Weng, 2017: Impacts of assimilating all or GOES-like AHI infrared channels radiances on QPFs over Eastern China. Tellus A, 69, 1345265, doi: 10.1080/16000870.2017.1345265.

Saunders, R. W., M. Matricardi, and P. Brunel, 1999: An improved fast radiative transfer model for assimilation of satellite radiance observations. Quart. J. Roy. Meteor. Soc., 125, 1407-1425.

Saunders, R., P. Rayer, P. Brunel, A. Von Engeln, N. Bormann, L. Strow, S. Hannon, S. Heilliette, X. Liu, F. Miskolczi, Y. Han, G. Masiello, J.-L. Moncet, G. Uymin, V. Sherlock, and D. S. Turner, 2007: A comparison of radiative transfer models for simulating Atmospheric Infrared Sounder (AIRS) radiances. J. Geophys. Res., 112, D01S90, doi:10.1029/2006JD 007088.

Shen, Y., P. Zhao, Y. Pan, and J. Yu, 2014: A high spatiotemporal gauge-satellite merged precipitation analysis over China. J. Geophys. Res., 119, 3063-3075.

Simmons, A. J., and A. Hollingsworth, 2002: Some aspects of the improvement in skill of numerical weather prediction. Quart. J. Roy. Meteor. Soc., 128, 647-677.

Skamarock, W. C., J. B. Klemp, J. Dudhia, D. O. Gill, D. M. Barker, M. G Duda, X.-Y. Huang, W. Wang, and J. G. Powers, 2008: A description of the Advanced Research WRF Version 3. NCAR Tech. Note NCAR/ TN-475+STR, 113 pp., doi:10.5065/D68S4MVH.

Wang, A., and X. Zeng, 2012: Evaluation of multireanalysis products with in situ observations over the Tibetan Plateau. J. Geophys. Res., 117, D05102, doi:10.1029/ 2011JD016553.

Weng, F., 2007: Advances in radiative transfer modeling in support of satellite data assimilation. J. Atmos. Sci., 64, 3799-3807.

Wilks, D. S., 1995: Statistical Methods in the Atmospheric Sciences: An Introduction. Academic Press, 467 pp.

Wu, W.-S., R. J. Purser, and D. F. Parrish, 2002: Threedimensional variational analysis with spatially inhomogeneous covariances. Mon. Wea. Rev., 130, 29052916.

Zhao, T., J. Wang, and A. Dai, 2015: Evaluation of atmospheric precipitable water from reanalysis products using homogenized radiosonde observations over China. J. Geophys. Res., 120, 10703-10727.

Zou, X., A. Barcilon, I. M. Navon, J. Whitaker, and D. G. Cacuci, 1993: An adjoint sensitivity study of blocking in a two-layer isentropic model. Mon. Wea. Rev., 121, 2833-2857.

Zou, X., Z. Qin, and F. Weng, 2011: Improved coastal precipitation forecasts with direct assimilation of GOES11/12 imager radiances. Mon. Wea. Rev., 139, 37113729.

Zou, X., Y. Ma, and Z. Qin, 2012: Fengyun-3B Microwave Humidity Sounder (MWHS) data noise characterization and filtering using principle component analysis. IEEE Trans. Geosci. Remote Sens., 50, 4892-4902. 
Zou, X., F. Weng, B. Zhang, L. Lin, Z. Qin, and V. Tallapragada, 2013a: Impact of assimilation of ATMS data in HWRF on track and intensity forecasts of 2012 four landfall hurricanes. J. Geophys. Res., 118, 11558-11576.

Zou, X., Z. Qin, and F. Weng, 2013b: Improved quantitative precipitation forecasts by MHS radiance data assimilation with a newly added cloud detection algorithm. Mon. Wea. Rev., 141, 3203-3221.

Zou, X., Z. Qin, and Y. Zheng, 2015: Improved tropical storm forecasts with GOES-13/15 imager radiance assimilation and asymmetric vortex initialization in HWRF. Mon. Wea. Rev., 143, 2485-2505.

Zou, X., Z. Qin, and F. Weng, 2016: Impact of dawn-dusk satellite AMSU-A data on quantitative precipitation forecasts and the implications for three-orbit constellation. Chinese J. Atmos. Sci., 1, 46-62.

Zou, X., Z. Qin, and F. Weng, 2017: Impacts from assimilation of one data stream of AMSU-A and MHS radiances on quantitative precipitation forecasts. Quart. J. Roy. Meteor. Soc., 143, 731-743. 